\title{
ON THE INITIATION OF NEARSHORE MORPHOLOGICAL RHYTHMICITY
}

\author{
M.A. de Schipper ${ }^{1}$, R. Ranasinghe ${ }^{1,2}$, A.J.H.M. Reniers ${ }^{3}$ and M.J.F. Stive ${ }^{1}$ \\ Nearshore rhythmicity is often initiated in the period just after a storm where the subtidal bar is turned alongshore \\ uniform. The initiation time as well as the length scales of the created rhythmicity varies from one storm period to \\ another. Here we show that the post-storm wave conditions are related to the initiation of the morphological \\ rhythmicity. Narrow-banded and long wave period, both proxies for swell waves, are often found to be present prior \\ to the initiation of rhythmicity. Furthermore, numerical model computations illustrate that swell waves induce \\ significantly larger wave group induced velocities on the bar. These findings imply that the arrival of swell waves can \\ initiate and stimulate the nearshore morphological rhythmicity.
}

Keywords: Rhythmicity; Nearshore sandbars; Wave groups

\section{INTRODUCTION}

The nearshore subaqueous zone is the most active part of the coastal profile. Often this part is characterized by the presence of one or more subtidal bars. These bars are frequently found to be rhythmic; meaning that both cross shore location of the bar as well as the crest height are alongshore variable (a characteristic bar rip system). During high energy (storm) events, these bars tend to move offshore and lose their alongshore variability turning the bar alongshore uniform. This is also referred to as a reset event, since all pre-storm rhythmicity is removed. In the days subsequent to the storm the bar transforms back into an alongshore variable shape. In time, under continued accretive wave conditions, the shoals eventually weld onto the shoreline creating a low tide terrace under favorable conditions (Wright and Short, 1984). For a storm to be a true reset this developing post-storm rhythmicity is uncorrelated with the pre-storm rhythmicity.

The length scales of the rhythmic patterns are highly variable. A comparison of over 30 sites around the globe in van Enckevort et al. (2004) shows that the rhythmic spacing can differ from one site to another by a factor of 40 ( $\approx 50 \mathrm{~m}$ to $2 \mathrm{~km}$ ). Moreover, at a particular site at a single moment in time the spacing also varies considerably in the alongshore direction, implying a more or less stochastic generation process (Holman et al., 2006). Beside the variations in mean rip spacing from site to site and the large variation around the mean rip spacing, the spacing also varies from one post-reset period to another (Holman et al., 2006 ; figure 4 therein).

The present study focuses on the short post-reset period where the morphological rhythmicity is initiated, aiming to get insight why the initiation differs from one post-reset period to another.

Various mechanisms have been proposed for the formation of the nearshore rhythmicity, which can be characterized as forced, free and quasi-forced behavior.

Forced behavior implies that the hydrodynamic forcing offshore of the bar contains an alongshore length scale which is imposed on the topography, such as the presence of offshore submarine canyons causing alongshore varying wave conditions (Long and Özkan-Haller, 2005) or coupling with a crescentic outer bar (Castelle et al., 2010) located offshore of the subtidal bar.

Free behavior (also called self organization) states that there is no alongshore length scale present in the offshore forcing that is responsible for the initiated length scale. The evolving length scales hence are solely determined by interaction between the morphology and the feedback mechanisms in the fluid and sediment motion. Small perturbations in topography or forcing will trigger instabilities that will grow to specific preferred length scales like eigenmodes of the system. Based on the self organization mechanism the rhythmicity has been predicted using process based numerical modeling (e.g. Christensen et al., 2002) or linear stability models (e.g. Calvete et al., 2007). Although the forcing in these models contains no preferred length scale, the developing rhythmicity remains a function of the forcing as wave height variations lead to different patterns (Calvete et al., 2005).

The last category, the quasi forced behavior counts on an alongshore length scale in the forcing in the system to make a small rhythmic perturbation which is then further enhanced by the feedback.

\footnotetext{
${ }^{1}$ Faculty of Civil Engineering and Geosciences, Section of Hydraulic Engineering, Delft University of Technology, Stevinweg 1, 2628CN, Delft, The Netherlands

2 UNESCO-IHE Institute for Water Education, Westvest 7, 2611 AX, Delft, The Netherlands

${ }^{3}$ Rosenstiel School of Marine and Atmospheric Science (RSMAS), University of Miami, 4600 Rickenbacker Causeway, FL 33149-1098, Miami, USA
} 
Quasi forced behavior is consequently a combination of both free and forced behavior. Although the forcing mechanism itself is not capable of producing very large topographic changes, the initiated length scale will be based on its footprint. Key element for the quasi forced behavior is that the length scale in the forcing has a length scale close to that eigenmode of the system for the feedback to enhance the features. Reniers et al. (2004) propose that very low frequency (VLF) motions $(f<0.004$ $\mathrm{Hz}$ ) in the surfzone are responsible for the generation of nearshore rhythmicity. These very low frequency motions originate from the wave group forcing and scour small variations on the bar with the length scale similar to the alongshore size of the VLF vortices. The model results show a bathymetric evolution with a final length scale that correlates well with the length scales of the VLF's. Although the VLF's themselves have a timescale that is too short to scour deep rip channels, the length scale they impose is enhanced by the morphodynamic feedback.

Strikingly, all these mechanisms have been capable of explaining patterns in the range of the observed rip channels spacing, leaving the discussion of the true mechanism(s) behind the initiation of nearshore rhythmicity open to present day. Nevertheless, the reported variations in rhythmicity spacing over the last decades led to shift in thinking, believing that the nearshore sand bar rhythmicity is more a result of free or quasi-forced than forced behavior (Coco and Murray, 2007).

Various authors (Turner et al., 2007; amongst others) have attempted to correlate the concurring wave conditions to the observed rhythmicity or rip spacing for an extended time period. Generally, this correlation is very weak. It revealed that once a pattern has developed, it can be very persistent (Holman et al., 2006). This indicates that the rhythmicity in the nearshore rapidly becomes topographically controlled instead of offshore forced and despite the widely varying wave conditions the rhythmic patterns remain unaltered (e.g. Smit et al., this issue). The only instant that the rhythmicity and its initiation would be correlated and affected by the concurrent wave conditions would be the short post-reset period, when the bar turns rhythmic from an alongshore uniform bar.

The current work adds to the previous studies by investigating several post-reset initiation periods and their concurrent wave conditions. It is hypothesized that the shape of short wave spectrum (frequencies between 0.04 and $0.5 \mathrm{~Hz}$ ) of the concurrent wave conditions is of influence on the postreset development. The shape of the short wave spectrum determines the groupiness (size and succession rate of wave groups) of the short waves. Narrow-banded spectra with long wave periods, often described as swell waves, lead to very regular long crested waves. As a result, wave groups have a large spatial size (Figure 1 a,b ). Wide banded wave spectra, also referred to as wind sea spectra, have a more chaotic short wave surface elevation and consequently smaller size wave groups (Figure 1 c,d ).

The spatial extend of the wave groups is considered to have a large impact on the nearshore velocities. The arrival and reflection of a single wave group induces infragravity $(0.004<f<0.04 \mathrm{~Hz})$ velocities in the order of $1 \mathrm{~m} / \mathrm{s}$. In addition, the interaction of multiple wave groups with the topography leads to the generation of very low frequency velocity patterns $(f<0.004 \mathrm{~Hz})$ with a magnitude in the order of $0.5 \mathrm{~m} / \mathrm{s}$ (Reniers et al., 2004). In case multiple wave groups arrive approximately at the same alongshore location, a persistent VLF eddy pattern can be generated that can persist up to 40 minutes (Long and Özkan-Haller, 2009). The persistence and trajectory of the VLF motions is predominately determined by the incident wave conditions. As such, the presence of directionally and frequency spread waves is directly linked to the generation of the VLF motions (MacMahan et al., 2010).

Here we investigate using field data if narrow-banded long wave period conditions are indeed present at the initiation of rhythmicity and secondly if the observed changes in short wave spectrum significantly influence the wave group induced velocities on the bar. 

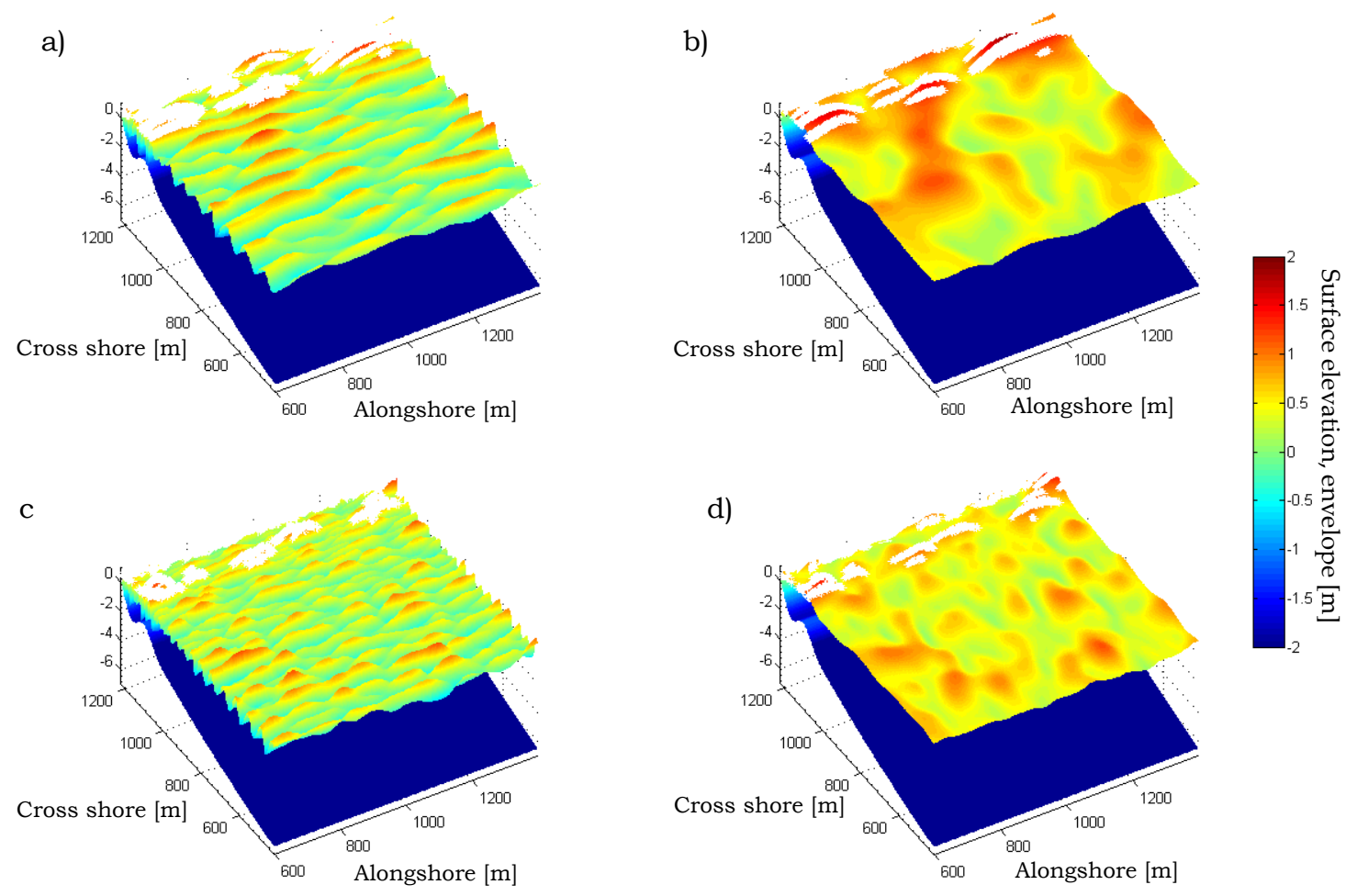

Figure 1. Model computations of short wave surface elevations under long period narrow-banded swell waves (a) and wide banded wind sea (c). Bottom topography in blue, breaking wave crests in white. Short wave envelopes for swell (c) and wind sea (d) show the impact of the spectral bandwidth on the spatial size of the wave groups.

\section{FIELD CASE}

\section{Study area}

Initiation of rhythmicity was investigated at Palm Beach, Australia (Figure 2). Palm Beach, a $2 \mathrm{~km}$ long embayed beach located $30 \mathrm{~km}$ north of Sydney, was selected due to the presence of a single subtidal bar, minimizing the effect of coupling with offshore features. The field site is equipped with an Argus imaging station and a nearby offshore wave buoy, making it possible to follow rhythmicity on a day-to-day basis with the concurrent wave conditions. The wave climate at Palm Beach is characterized as combination of a highly variable wind wave climate superimposed on persistent southeasterly swell. Mean deep water significant wave height is $1.59 \mathrm{~m}$ and mean wave period $10 \mathrm{~s}$ (Short and Trenaman, 1992 in Brander, 1999). The surfzone bed slope is 0.02 flattening to 0.005 seaward of $1 \mathrm{~km}$ offshore (Brander, 1999) providing a platform for the waves to refract inshore before they reach the surf zone.

The beach experiences all beach states described in Wright and Short (1984), going through the full cycle of an alongshore uniform bar just after a storm evolving into a Rhythmic Bar Beach (RBB), a Transverse

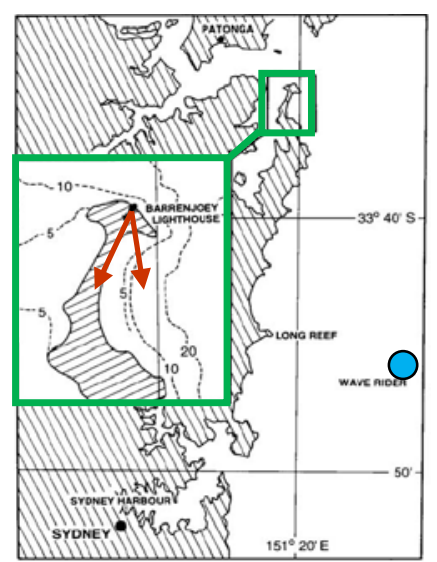

Figure 2. Palm beach field site Arrows indicate the orientation of the Argus station. Bar Rip (TBR) finally arriving at a Low Tide Terrace (LTT). Yearly around 5 reset storms fully erase the existing rhythmicity, after which new post-storm rhythmicity initiated (Ranasinghe et al., 2004, Holman et al., 2006). 


\section{Argus video images}

Daily Argus images of the beach were used to derive the initiation of rhythmicity. The Argus video images (Holman and Stanley, 2007) are taken from the Barrenjoey Lighthouse at $115 \mathrm{~m}$ above mean sea level looking southwards towards the bay (Figure 2). To complement the work of Holman et al. (2006), the present data analysis is based on the same images collected at Palm Beach in the period 1996 to 1999. Although the station consists of two cameras, only camera 1 is used which overlooks the majority of the beach (Figure 3). The station collects time-exposure (timex) images every daylight hour. These time exposure images are created by averaging the first $10 \mathrm{~min}$ of continuous $1 \mathrm{~Hz}$ images. Finally, to minimize the influence of the varying water level over the tidal cycle the hourly images are averaged over the day giving a daily timex image. Areas with consistent wave breaking show up in these timex images as high intensity (white) bands (Lippman and Holman, 1989). Wave breaking is mostly determined by water depth, and therefore the areas with consistent wave breaking are located at the sand bar. The maximum intensity in this band corresponds to the maximum wave breaking, which is at or close to the bar crest location. Using simultaneous bathymetric surveys and Argus video observations Van Enckevort and Ruessink (2001) show that this provides a reliable estimate of the bar crest position in the order of $10 \mathrm{~m}$.

A plan view image of the bar location is created by rectifying the daily timex images and converting these into real world coordinates using the technique described in Holland et al. (1997) (Figure 3).
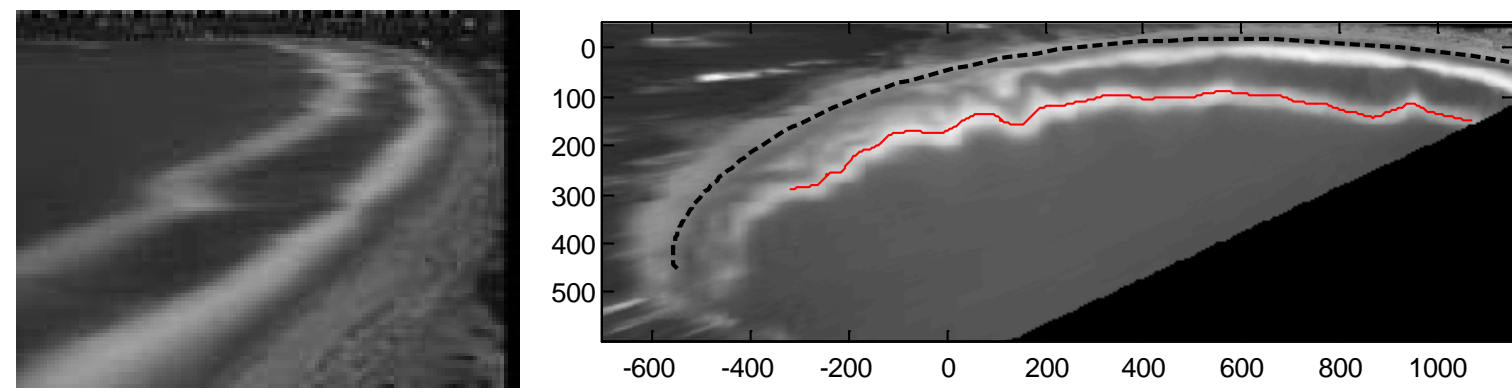

Figure 3. Daily time exposure image on May $17^{\text {th }} 1997$ (left) and rectified image (right). Bar intensity line is indicated by the thin red line, approx. shoreline location is given by the thick dashed line.

The rectified images are used to derive the bar location in real world coordinates. Shoreline position is given by a log spiral (Ranasinghe et al, 2004) indicating its approximate position. Next the maximum intensity in the white band in the images is computed semi-automatically using the BLIM toolbox developed at Utrecht University (Pape, 2008). Since the bar rhythmicity is more visible in the northern half of the embayment and the pixel resolution decreases towards the south, the southern 500 $\mathrm{m}$ of the bay is not included further analysis, leaving approximately $1100 \mathrm{~m}$ of bar crest line to be analyzed.

The bar crest line position is subtracted from the shoreline position to obtain the bar location with respect to the beach. Mean bar position is subtracted, leaving only the rhythmicity of the bar crest with respect to the mean position, regardless of the cross shore movement of the bar in the days after the storm (Figure 4).

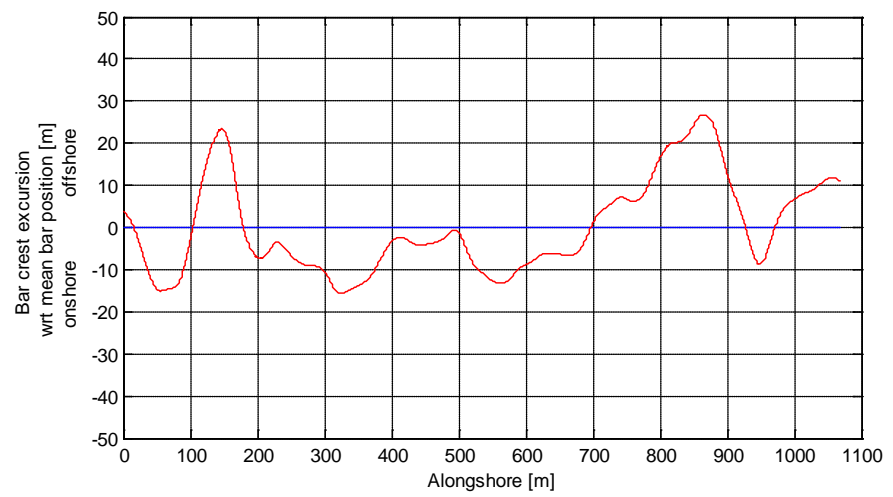

Figure 4. Bar crest rhythmicity (excursion with respect to the mean bar location) on May $17^{\text {th }} 1997$ (Figure 3). 
The rhythmicity amplitude $R$ is determined to obtain a daily objective value of the rhythmicity. Rhythmicity $R$ is computed by performing a Fourier decomposition of the alongshore bar crest rhythmicity line depicted in Figure 4, and taking the root mean variance in the 200 to $500 \mathrm{~m}$ band (Plant et al., 2006).

\section{Waves}

Incident offshore wave conditions are obtained from the Long Reef wave buoy (Figure 2). The directional wave rider is located $20 \mathrm{~km}$ south of the site in a water depth of $87 \mathrm{~m}$. Hourly significant wave height $H_{s}$ and one dimensional frequency spectra are obtained for the reset events described in Holman et al. (2006).

The one dimensional frequency spectra provide information on the distribution of wave energy in 64 bands of $0.005 \mathrm{~Hz}$ ranging from $0.005 \mathrm{~Hz}$ to $0.32 \mathrm{~Hz}$. The spectral bandwidth of the spectra is calculated using the method of Van Vledder (1992). First the spectra are moving averaged over a time span of 3 hours. Next the zeroth-, first- and second-order moments of the spectrum are calculated using:

$$
\mathrm{m}_{\mathrm{n}}=\sum_{0.005}^{0.32} f^{n} E(f) \Delta f
$$

To obtain reliable estimates of mean period and spectral bandwidth, the statistical parameters $T_{m 01}$ and $k$ are then calculated. Parameters $T_{m 01}$ and $k$ are less influenced by high frequency noise than the more commonly used zero crossing period $T_{z}$ and Longuet-Higgins bandwidth parameter $v$ (Van Vledder, 1992), and are therefore used for further analysis.

Spectral bandwidth $k$ is calculated as follows:

$$
k=1 / m_{0}^{2}\left\{\left[\sum_{0.005}^{0.32} E(f) \cos \left(\frac{2 \pi f}{f_{0}}\right) \Delta f\right]^{2}+\left[\sum_{0.005}^{0.32} E(f) \sin \left(\frac{2 \pi f}{\overline{f_{0}}}\right) \Delta f\right]^{2}\right\}
$$

Using $\overline{f_{0}}=\sqrt{m_{2} / m_{0}}$, and

$$
T_{m 01}=\frac{m_{0}}{m_{1}} .
$$

Theoretically, Pierson-Moskowitz spectra of fully developed sea states have a spectral bandwidth value $k$ equal to 0.37 and the more narrow peak enhanced JONSWAP spectrum has a value $k=0.55$. Measured spectral bandwidth values are typically in the order of 0.45 .

\section{Results}

The resets reported in Holman et al. (2006) are investigated, 12 in total. Occasionally reset storms lead to malfunctioning of the wave buoy or blurred camera images, making it impossible to observe the onset of the rhythmicity for 3 reset periods. Remaining 9 post-reset periods show a very rapid initiation of the rhythmicity ranging from one day to five days after the peak of the storm. The resets show a remarkable diversity in post-reset behavior. On some occasions the rhythmicity appears to be initiated at the beach, and the nearshore bar reacts later. In other occasions the bar itself is very rapidly becoming rhythmic and the inshore region follows.

The post-reset morphological response can be subdivided into two categories, one category where the storm is followed by immediate rhythmicity in the nearshore without delay and another category where the nearshore bar stays alongshore uniform for a few days before the first rhythmicity emerges.

Rhythmicity parameter $R$, ranges from values around 1 near the peak of the storm and increase beyond 3 at the reoccurrence. The transition between alongshore uniform bar and the start of a rhythmic bar is determined based on the rhythmicity values as well as visual observation. Spectral bandwidth values $k$ of the wave conditions range from 0.3 to 0.65 in the post-reset periods, where the very low values are often due to double peaked spectra in the lee of the storm.

Six post-reset periods fall in the first category characterized by a very rapid reoccurrence of rhythmicity in the lee of the storm. Within two days after the peak of the storm the bar crest line becomes rhythmic, often preceded by alongshore difference in wave breaking zones closer to shore. 


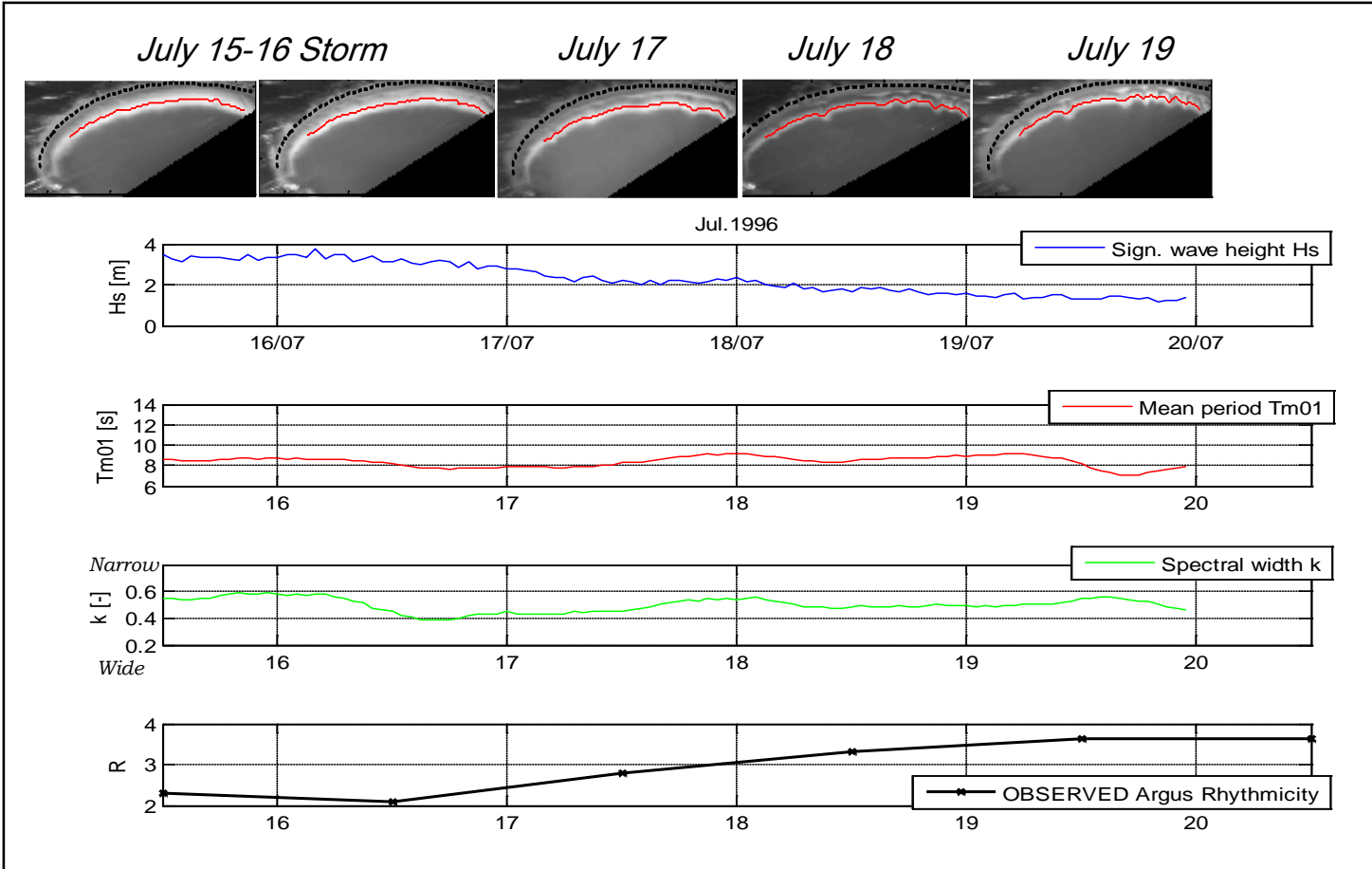

Figure 5. Development of rhythmicity at Palm Beach, Australia. Rapid re-occurrence of rhythmicity in the lee of the storm of July 1996. Rectified ARGUS images (top) show rhythmic pattern emerging in the lee of the storm on July $17^{\text {th }}$. The bar crest line is shown in red. Concurrent wave data (bottom) show narrow banded waves during the storm.

May 9-12 Storm

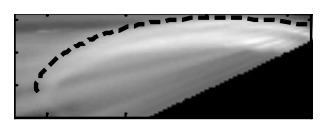

$$
\text { May } 13
$$

May 15
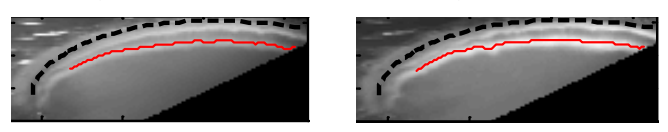

May 17
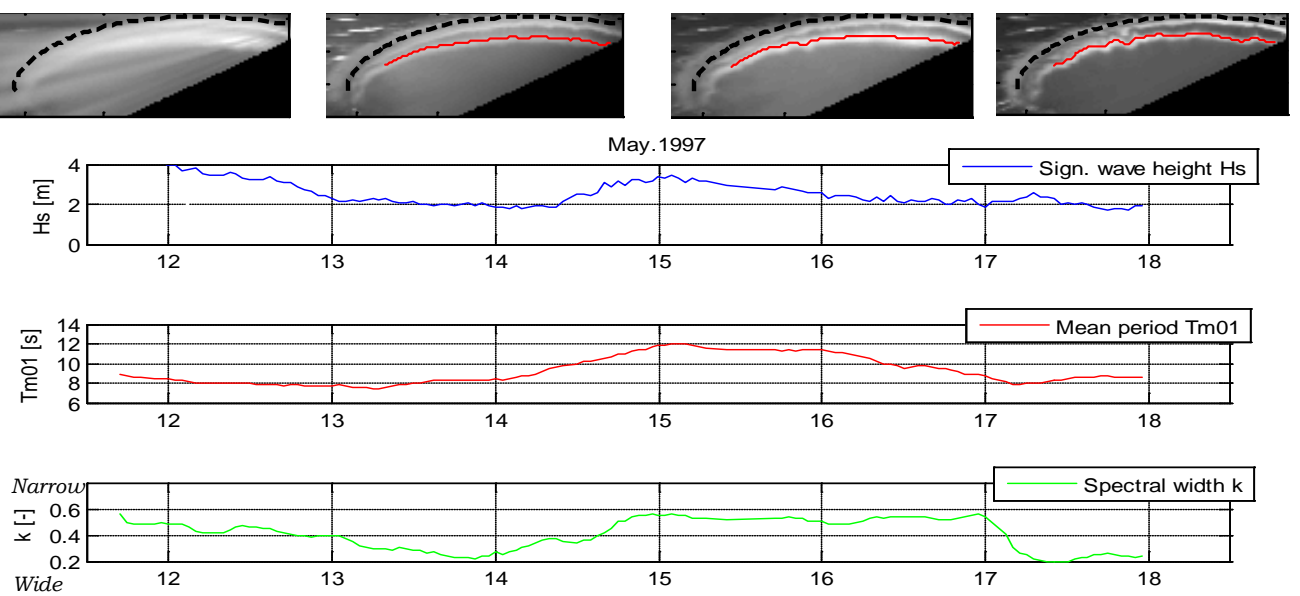

Wide

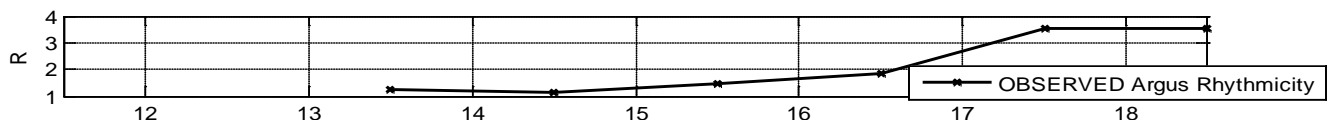

Figure 6. Development of rhythmicity at Palm Beach, Australia. Postponed re-occurrence of rhythmicity after the storm of May 1997. Rectified ARGUS images (top) show rhythmic patterns emerging on May $15^{\text {th }}$. The bar crest line is shown in red. Concurrent wave data (bottom) show two days $\left(15^{\text {th }}-17^{\text {th }}\right)$ of high period, narrow banded waves associated with the morphological transition. 
Figure 5 shows the morphological evolution after the storm of July 1996. Already during the storm the wave field is very narrow-banded with $k$ values up to 0.6 . Just after the peak of the storm the first patterns can be observed at the beach and after 3 to 4 days a very rhythmic bar rip channel morphology is established.

The other category, were the bar remains alongshore uniform for a few days is exceptional. Figure 6 shows the morphological evolution after the storm of May 1997. Here it is clear that the rhythmicity develops much slower. Two days after the storm (May $13^{\text {th }}$ ) the bar is still alongshore uniform, and the first rhythmic features emerge 4 days after the peak of the storm on May $15^{\text {th }}$. Daily averaged wave spectra for May $13^{\text {th }}$ and $15^{\text {th }}$ (Figure 7 ), show that significant lowering of the peak frequency and narrowing of the spectrum has taken place, and the spectrum on May $15^{\text {th }}$ corresponds to narrowbanded swell conditions.

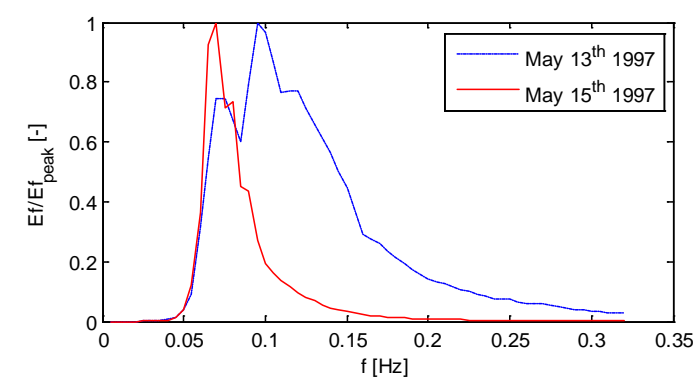

Figure 7. Normalized daily averaged frequency spectra for the May 1997 reset.

In general the field data reveals that if the post-reset conditions are narrow-banded, the rhythmicity is initiated without delay. On the other hand, if the storm is succeeded by a period of wide banded 'wind sea' the initiation of rhythmicity is postponed until the first swell arrives.

\section{HYDRODYNAMIC MODELLING}

\section{Introduction}

The relation between spectral characteristics of the short waves and the initiation of rhythmicity as found in the field case is further explored with numerical modeling of the nearshore hydrodynamics.

The objective is to assess the impact of the shift in spectral characteristics in the post-reset period on the nearshore flow field. If indeed the narrow-banded low frequency spectra are related to the initiation of rhythmicity, this should lead to a significant increase in nearshore flow velocities.

\section{Model description}

The surfzone flow driven by directionally and frequency spread waves contains low frequency oscillations in with temporal scale of $O(10 \mathrm{~min})$ with alongshore scales of $O(250 \mathrm{~m})$. Capturing these low frequency motions in a short wave resolving approach is very time consuming, and therefore a short wave averaged approach is used. The model utilized is a research version of the Delft3D flow model as described in Reniers et al. (2004) and solves the short wave averaged depth-averaged nonlinear shallow water equations. Only the main features of the model are discussed here, as a complete model description and laboratory validation is given in Reniers et al. (2004).

The model is forced at the offshore boundary with time and alongshore varying wave group energy. This wave energy boundary condition is computed in two steps: first the short wave surface elevation at the boundary is constructed out of the two-dimensional frequency-direction short wave spectrum with a random phase approach (Van Dongeren et al., 2003). Next the envelope $A_{e n v}$ of the surface elevation is computed using a Hilbert transform followed by a low pass filter ( $f_{\text {cutoff }}=0.04 \mathrm{~Hz}$ ). Finally, the wave group envelope is transformed into wave group energy:

$$
E_{w, \text { offshore }}(y, t)=\frac{1}{2} \rho g A_{e n v}(y, t)^{2}
$$

The wave energy as imposed at the offshore boundary is propagated trough the domain using a wave energy balance: 


$$
\frac{\partial E_{w}}{\partial t}+\frac{\partial E_{w} c_{g} \cos \theta}{\partial x}+\frac{\partial E_{w} c_{g} \sin \theta}{\partial y}=-D_{w}
$$

Where the wave group speed $c_{g}$ is calculated with the peak period and wave direction $\theta$ is obtained from an initial HISWA computation (Holthuijsen et al., 1989). Wave energy dissipation $D_{w}$ is computed using the dissipation formulation of Roelvink (1993). Wave energy dissipation is further transformed into roller energy with a roller energy balance. The use of roller energy is important for a correct representation of the lateral mixing by eddy viscosity as well as the wave breaking induced mass flux.

The wave and roller energy balances are used to compute the radiation stresses (Reniers et al., 2002) throughout the domain. Spatial gradients in the radiation stress determine the wave forces $F_{x}$ and $F_{y}$ that are driving the cross- and alongshore flow momentum balances.

Flow velocities $u$ and $v$ are calculated in a Generalized Lagrangian Mean approach including the effect of wave induced drift on the depth averaged velocity approach (Walstra et al., 2000). Eulerian velocities (velocity with respect to the bed) are calculated by subtracting the depth averaged stokes drift velocity $u^{s}$ from the computed velocities:

$$
u^{E}=u-u^{s}
$$

Including the Stokes drift in the GLM method leads to significantly larger offshore velocities in the surfzone compensating the mass transport in the roller.

\section{Model domain}

A numerical model domain is set-up with approximately the dimensions of Palm Beach, $1.5 \mathrm{~km}$ in alongshore direction and almost $1.3 \mathrm{~km}$ in cross shore. Grid sizes are $10 \mathrm{~m}$ in alongshore and ranging from 4 to $25 \mathrm{~m}$ in the cross shore direction depending on the water depth.

The beach profile is chosen such that it corresponds to a post-reset bottom topography. It is alongshore uniform with a single bar (Figure 8). The bar crest is located $115 \mathrm{~m}$ from the shoreline, which is similar to the bar crest distance derived from the post-reset Argus images.

Lateral boundaries are closed to mimic an embayed beach, at offshore boundary a Riemann boundary is applied to enable outgoing long waves to leave the domain.

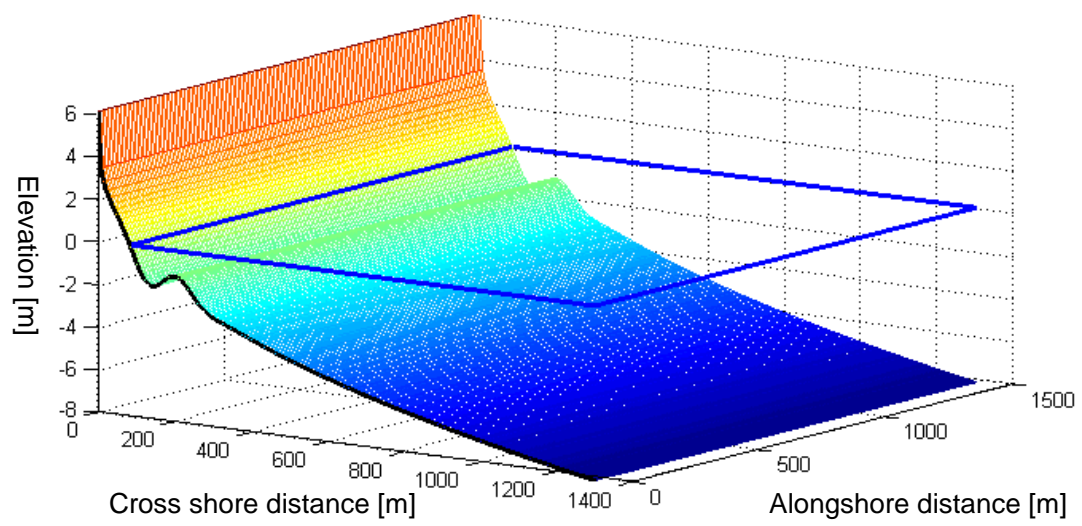

Figure 8. Bottom topography, still water level indicated by the blue lines.

\section{Numerical experiment}

Several wave conditions are modeled to represent post-reset wave conditions, ranging from very narrow-banded to very wide-banded. Wave height and directional width of the spectra are kept constant throughout the tests, to focus on only the spectral shape of the frequency spectrum.

Two types of tests are executed, with synthetic and measured spectra (Table 1). The measured spectra are the daily averaged spectra as measured during the Palm Beach reset of May 1997 and shown in Figure 7. Model tests with the synthetic spectra are to investigate the influence of changes in peak period and spectral width individually. 


\begin{tabular}{|c|c|c|c|c|}
\hline & & $H_{r m s}(\mathrm{~m})$ & $T_{p}(\mathrm{~s})$ & $k(-)$ \\
\hline JONSWAP, Reference case & TEST001 & 1.0 & 10 & 0.55 \\
\hline JONSWAP, $\gamma=10$ (narrow-banded) & TEST002 & 1.0 & 10 & 0.72 \\
\hline JONSWAP, $\gamma=1$ (wide-banded) & TEST003 & 1.0 & 10 & 0.37 \\
\hline JONSWAP, Increased period $T_{p}$ & TEST005 & 1.0 & 14 & 0.55 \\
\hline May $13^{\text {th }}, 1997$ (wide-banded) & TEST011 & 1.0 & 10.5 & 0.3 \\
\hline May $15^{\text {th }}, 1997$ (narrow-banded) & TEST012 & 1.0 & 14.3 & 0.55 \\
\hline
\end{tabular}

For the model tests with the synthetic spectra the JONSWAP spectrum is used, given by:

$$
E_{\text {JONSWAP }}(f)=\alpha g^{2}(2 \pi)^{-4} f^{-5} \exp \left[-\frac{5}{4}\left(\frac{f}{f_{p}}\right)^{-4}\right] \gamma^{\exp \left[-\frac{1}{2}\left(\frac{f I f_{p}-1}{\sigma}\right)^{2}\right]} \text {. }
$$

The most right hand term of Eq. 7 is a peak enhancement function $\gamma^{\exp \left[-\frac{1}{2}\left(\frac{f I f_{\rho}-1}{\sigma}\right)^{2}\right]}$, where $\gamma$ is usually chosen to be equal to 3.3. Varying $\gamma$ makes it possible to adapt the spectral bandwidth of the spectrum while keeping the total amount of wave energy constant. Using $\gamma$ equal to 1 results in a Pierson-Moskowitz spectrum which is relatively wide. Larger values of $\gamma$ lead to an increase of the peak enhancement function, and more narrow-banded spectra.

Frequency spectra are multiplied by a normalized directional distribution $D$ to obtain a twodimensional frequency directional spectrum (Figure 9). Distribution $D$ is defined as follows:

$$
D(\theta)=A^{*} \cos ^{s} \theta
$$

Where exponent $s$ controls the directional width of the spectrum and parameter $A^{*}$ is chosen such that the total amount of energy is conserved. For the present study this directional width is kept constant at a single sided directional width of 12.2 degrees (s equal to 20).

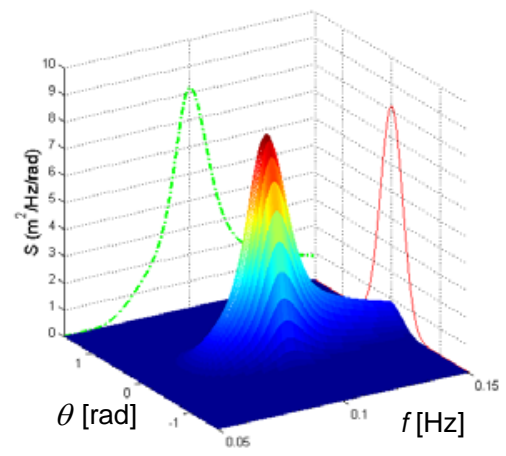

Figure 9. Two dimensional frequency-direction spectrum for TEST001, frequency spectrum as calculated with Eq. 7 is given by the green dash dotted line.

The hydrodynamics are modeled for a total of 180 minutes with a hydrodynamic time step of 2.4 seconds. Horizontal and vertical tides are omitted, as well as wind driven flows. 


\section{Post processing}

For each of the test cases in Table 1, the computed velocities on the bar crest are evaluated. The wave group forcing on the offshore boundary forces infragravity motions bound to the incoming wave groups, free reflected infragravity waves and very low frequency (VLF) motions. Velocities on the bar are analyzed and the contributions in the VLF and infragravity band are separated using Fourier analysis. Velocity spectra are alongshore averaged to remove the noise and the root mean squared velocity amplitudes are determined for each band (Figure 10).

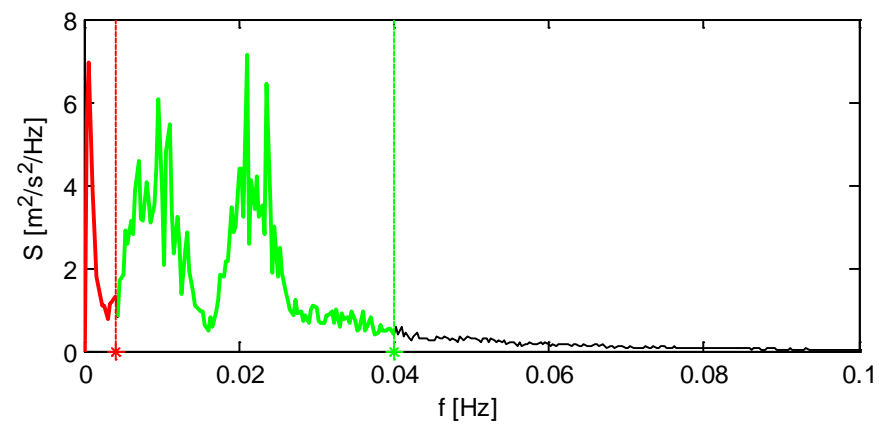

Figure 10. Alongshore averaged cross shore velocity spectrum at the bar crest for TEST001. Velocities in the VLF and infragravity band are shown in red and green respectively. Note that the short waves are not resolved in the model and therefore not present in the spectrum.

\section{Results}

Measured spectra

The model computations (TEST011 and TEST012) using the measured daily averaged short wave spectra (Figure 7) show the impact of the post-reset wave conditions. May $13^{\text {th }}$ is during the period in between the storm and the initiation (Figure 6). Conditions are wide banded $(k=0.3)$ with a relatively short peak period of $10.5 \mathrm{~s}$. May $15^{\text {th }}$ spectrum is just before the initiation of the rhythmicity and conditions are narrow-banded $(k=0.55)$ with a long peak period of $14.3 \mathrm{~s}$.

Model computations show short wave averaged velocities on the bar at a water depth of $1.2 \mathrm{~m}$ of $\mathrm{O}(0.5 \mathrm{~m} / \mathrm{s})$, with velocities in the VLF band of $\mathrm{O}(0.15 \mathrm{~m} / \mathrm{s})$. As can be expected with shore normal wave incidence, most energy is in the cross shore component of the velocities. Alongshore velocities in both infragravity and VLF bands are of $\mathrm{O}(0.1 \mathrm{~m} / \mathrm{s})$

Alongshore averaged transects of wave height and the cross shore wave group induced velocities for based on the spectra of May $13^{\text {th }}$ and May $15^{\text {th }}$ are depicted in Figure 11.

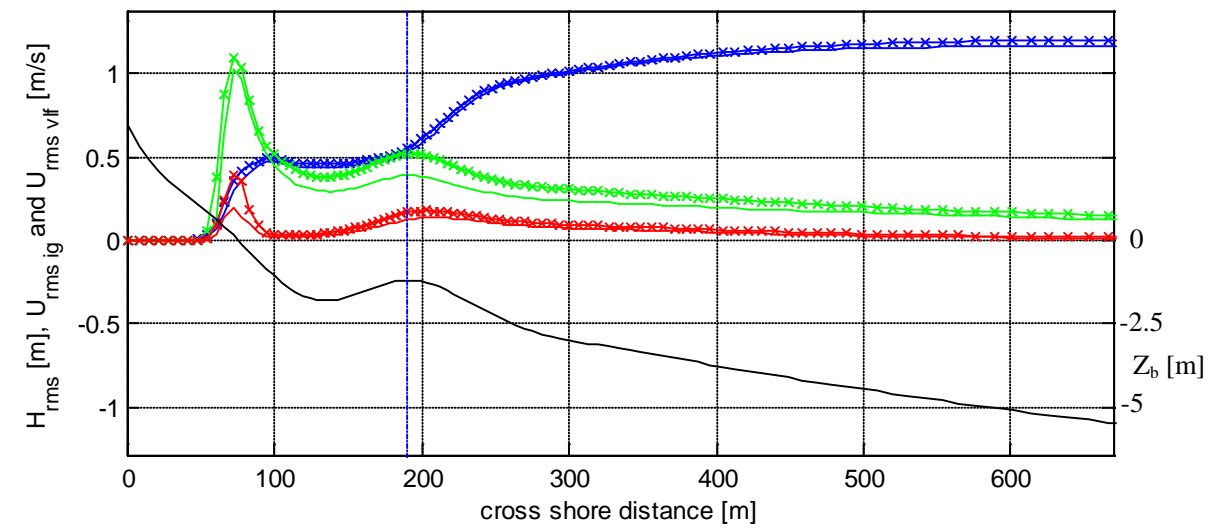

Figure 11. Alongshore averaged cross transect of $H_{r m s}$ (blue), and cross shore velocity components $U_{i g} r m s$ (green) and $U_{V L F r m s}(r e d)$. Results for broad banded spectra on May $13^{\text {th }}$ (solid lines) and May $15^{\text {th }}$ ( $-x-$ lines). Bottom profile in black solid line.

Even though the offshore wave height is equal for both tests, the velocities on the bar are significantly larger for the computation with the narrow-banded spectrum of May $15^{\text {th }}$. For comparison the magnitude computed velocities on the bar crest are listed in Table 2. 
Infragravity and VLF velocities are $O$ (30\%) larger for the narrow-banded long wave period conditions as measured May $15^{\text {th }}$. This holds for both cross and alongshore direction.

Computations show that a narrowing of the spectrum and the increase in wave period yields to a significant increase in wave group induced velocities. In practice the narrow banded frequency spectra often coincide with narrow directional distributions. It is hypothesized that including the variation in directional bandwidth would yield to even larger differences in computed velocities.

\begin{tabular}{|l|l|l|}
\hline \multicolumn{3}{|c|}{ Table 2. Computed velocities on the bar crest, measured spectra May 1997 reset } \\
\hline & $\begin{array}{l}\text { May 13th } \\
\text { Wide-banded }\end{array}$ & $\begin{array}{l}\text { May 15th } \\
\text { Narrow-banded }\end{array}$ \\
\hline Wave period $T_{p}$ & $10.5 \mathrm{~s}$ & $14.3 \mathrm{~s}$ \\
\hline Spectral bandwidth $k$ & 0.3 & 0.55 \\
\hline Offshore wave height $H_{r m s}$ & $1.0 \mathrm{~m}$ & $1.0 \mathrm{~m}$ \\
\hline Directional width s (Eq. 8) & 20 & 20 \\
\hline \multicolumn{3}{|l|}{$\mid$} \\
\hline Infragravity velocities $(0.004<f<0.04)$ at the bar crest \\
\hline$u_{i g_{-} r m s}$ & $0.39 \mathrm{~m} / \mathrm{s}$ & $0.52 \mathrm{~m} / \mathrm{s}$ \\
\hline$v_{i g_{-} r m s}$ & $0.08 \mathrm{~m} / \mathrm{s}$ & $0.12 \mathrm{~m} / \mathrm{s}$ \\
\hline & Very Low Frequency velocities $(f<0.004)$ at the bar crest \\
\hline$u_{V L F_{-} r m s}$ & $0.13 \mathrm{~m} / \mathrm{s}$ & $0.17 \mathrm{~m} / \mathrm{s}$ \\
\hline$v_{V L F_{-} r m s}$ & $0.08 \mathrm{~m} / \mathrm{s}$ & $0.11 \mathrm{~m} / \mathrm{s}$ \\
\hline
\end{tabular}

\section{Synthetic spectra}

The test cases on the synthetic spectra enable to look into more detail to the impact of spectral bandwidth and peak period separately. First three cases with ordinary JONSWAP and variable spectral bandwidth all show similar infragravity velocities (Table 3). Although the spatial size of the wave groups increases as the spectrum becomes narrower, the influence on the magnitude of the infragravity velocities is minimal. Velocities on the bar in the very low frequencies show an increase in the order of $20 \%$ in cross shore and $10 \%$ alongshore direction, as the spectrum narrows. The differences however cannot fully explain the large increase in velocities as observed in the computations of measured spectra in Table 2.

\begin{tabular}{|c|c|c|c|c|}
\hline & $\begin{array}{l}\text { Reference } \\
\text { Jonswap }(\gamma=3.3)\end{array}$ & $\begin{array}{l}\text { Wide-banded } \\
(\gamma=1)\end{array}$ & $\begin{array}{l}\text { Narrow-banded } \\
(\gamma=10)\end{array}$ & $\begin{array}{l}\text { Reference Jonswap }(\gamma=3.3) \\
\text { Increased period }\end{array}$ \\
\hline Wave period $T p$ & $10 \mathrm{~s}$ & $10 \mathrm{~s}$ & $10 \mathrm{~s}$ & $14 \mathrm{~s}$ \\
\hline Spectral bandwidth $k$ & 0.55 & 0.37 & 0.72 & 0.55 \\
\hline Offshore wave height $\mathrm{Hrms}$ & $1.0 \mathrm{~m}$ & $1.0 \mathrm{~m}$ & $1.0 \mathrm{~m}$ & $1.0 \mathrm{~m}$ \\
\hline Directional width s (Eq. 8) & 20 & 20 & 20 & 20 \\
\hline \multicolumn{5}{|c|}{ Infragravity velocities $(0.004<f<0.04)$ at the bar crest } \\
\hline$u_{i g_{-} r m s}$ & $0.38 \mathrm{~m} / \mathrm{s}$ & $0.37 \mathrm{~m} / \mathrm{s}$ & $0.36 \mathrm{~m} / \mathrm{s}$ & $0.49 \mathrm{~m} / \mathrm{s}$ \\
\hline$v_{i g_{-} r m s}$ & $0.08 \mathrm{~m} / \mathrm{s}$ & $0.08 \mathrm{~m} / \mathrm{s}$ & $0.08 \mathrm{~m} / \mathrm{s}$ & $0.12 \mathrm{~m} / \mathrm{s}$ \\
\hline \multicolumn{5}{|c|}{ Very Low Frequency velocities $(f<0.004)$ at the bar crest } \\
\hline$u_{V L F_{-} r m s}$ & $0.14 \mathrm{~m} / \mathrm{s}$ & $0.13 \mathrm{~m} / \mathrm{s}$ & $0.17 \mathrm{~m} / \mathrm{s}$ & $0.18 \mathrm{~m} / \mathrm{s}$ \\
\hline$V_{V L F_{-} r m s}$ & $0.09 \mathrm{~m} / \mathrm{s}$ & $0.08 \mathrm{~m} / \mathrm{s}$ & $0.10 \mathrm{~m} / \mathrm{s}$ & $0.12 \mathrm{~m} / \mathrm{s}$ \\
\hline
\end{tabular}


A comparison between a spectrum with peak period $10 \mathrm{~s}$ (TEST001) and a spectrum with increased period $14 \mathrm{~s}$ (TEST005), shows that the influence of wave period is significant on the velocities.

Infragravity and very low frequency velocities at the bar crest both increase with $25 \%$ in the cross shore direction and $50 \%$ in the alongshore direction.

The results of the tests listed in Table 3 show that a shift in spectral characteristics of the short wave spectrum leads to significantly larger velocities on the bar. Both spectral bandwidth and wave period have an impact on the wave induced velocities, where wave period has the largest influence on the magnitude of both infragravity and VLF velocities.

\section{CONCLUSIONS AND DISCUSSION}

The Palm Beach resets of 1996 to 1999 show the following behavior:

- The resets show a remarkable diversity in post-reset behavior. On some occasions fully developed rip channels, beach cusps and shoals are visible within days, where in other occasions the rhythmicity after 6 days is only limited to small plan view undulations of the bar crest.

- The different behavior can be partly explained by the concurrent wave conditions, where the analyzed field data from Palm Beach indicates that the reoccurrence of rhythmicity appears to be linked to more 'swell-like' wave conditions (high Tp and/or narrow bandwidth).

- If 'swell-like' wave conditions occur during or just after the storm, rhythmic features appear within a day. For these cases the storm is directly followed by a rhythmic bar beach. When the storm is succeeded by a period of 'wind sea' wave conditions, the formation is postponed.

Next the impact of a change in spectral parameters on the wave group induced velocities on the bar is investigated.

- A shift in peak period and narrowing of the spectrum leads to significantly larger velocities on the bar in the order of $30 \%$. Spectral bandwidth is of importance for the velocities in the VLF band, however the impact of a shift in peak period is much larger.

Concluding, the arrival of swell (narrow-banded, long wave period) waves can initiate and stimulate the rhythmicity just after a storm.

The initiation of rhythmicity at Palm Beach was found to be a highly unpredictable process, with a large amount of factors such as variations in wave angle, directional spreading, reset-storm intensity, bar crest height or wave height not investigated here. Initiation of rhythmicity is found to relate to the shape of the short wave spectrum, but due to the dependence on these other aspects the initiation cannot be predicted using the spectral shape alone.

The present research support the hypothesis that infragravity motions and VLF's are a quasi forcing mechanism for rhythmicity as proposed by Reniers et al. (2004) since these low frequency motions increase significantly with the arrival of a new swell. However, also with other mechanisms such as coupling with an outer bar (Castelle et al., 2010) or self organization (Calvete et al., 2005), an increase in velocities on the bar due to an arrival of swell waves will stimulate the growth of the rhythmicity.

Present results do not imply that rhythmicity can only be initiated by swell waves, since nearshore rhythmicity can also be found on coastal sea coasts with wave periods as low as 5 seconds. It is more likely that rhythmicity develops under all conditions, but swell conditions are more effective in initiating the rhythmicity and a quicker response is to be expected at swell coasts. 


\section{ACKNOWLEDGMENTS}

The project is funded by Ecoshape/Building with Nature under Project Code NTW 3.2. The authors would like to thank the ARGUS community for collecting the Palm Beach images and developing the BLIM toolbox. The NSW Department of Environment and Climate Change and Manly Hydraulics Laboratory are greatly acknowledged for the use of the Sydney wave buoy data.

\section{REFERENCES}

Brander, R.W, 1999. Field observations on the morphodynamic evolution of a low-energy rip current system, Marine Geology, 157, 199-217

Calvete, D., N. Dodd, A. Falques, and S. M. van Leeuwen, 2005. Morphological development of rip channel systems: Normal and near-normal wave incidence, J. Geophys. Res., 110.

Calvete, D., G. Coco, A. Falques and N. Dodd, 2007. (Un)predictability in rip channel systems, Geophys. Res. Lett., 34.

Castelle B., B.G. Ruessink, P. Bonneton, V. Marieu, N. Bruneau, T.D. Price, 2010. Coupling mechanisms in double sandbar systems. Part 1: Patterns and physical explanation. Earth Surface Processes and Landforms.

Christensen, E.D., Walstra, D.J., Emerat, N., 2002. Vertical variation of the flow across the surf zone. Coastal Engineering, 45, 169- 198.

Coco G, A.B. Murray, 2007. Patterns in the sand: from forcing templates to self-organization. Geomorphology, 91, 271-290.

Holland, K. T., R.A. Holman, T.C. Lippmann, J. Stanley, and N. Plant, 1997. Practical use of video imagery in nearshore oceanographic field studies, IEEE J. Oceanic Eng., 22(1), 81- 92.

Holman R.A., and J. Stanley, 2007. The history and technical capabilities of Argus, Coastal Engineering, 54, 477-491.

Holman R.A., G. Symonds, E.B. Thornton and R. Ranasinghe, 2006. Rip spacing and persistence on an embayed beach, J. Geophys. Res.,111

Holthuijsen, L.H., N. Booij, and T.H.C. Herbers, 1989. A prediction model for stationary short-crested waves in shallow water with ambient currents, Coastal Engineering, 13, $23-54$.

Lippmann, T.C. and R.A. Holman, 1989. Quantification of sand bar morphology: a video technique based on wave dissipation, J. Geophys. Res., 94

Long, J. W., and H. T. Özkan-Haller, 2005. Offshore controls on nearshore rip currents, J. Geophys. Res., 110.

Long, J. W., and H. T. Özkan-Haller, 2009. Low-frequency characteristics of wave group-forced vortices, J. Geophys. Res., 114.

MacMahan, J. H., A.J.H.M. Reniers, and E.B. Thornton, 2010. Vortical surf zone velocity fluctuations with 0(10) min period, J. Geophys. Res.,115.

Pape, L., 2008. BLIM toolbox manual. IMAU Report R08-02, Department of Physical Geography, Utrecht University, available from the author upon request.

Ranasinghe, R., G. Symonds, K. Black, and R. A. Holman, 2004. Morphodynamics of intermediate beaches: A video imaging and numerical modeling study, Coastal Engineering, 51, 629- 655.

Reniers, A.J.H.M., A.R. Van Dongeren, J.A. Battjes, and E.B. Thornton, 2002. Linear modeling of infragravity waves during Delilah, J. Geophys. Res., 107.

Reniers, A.J.H.M., J.A. Roelvink and E.B. Thornton, 2004. Morphodynamic modeling of an embayed beach under wave group forcing, J. Geophys. Res.,109

Plant, N.G., K.T. Holland, and R.A. Holman, 2006. A dynamical attractor governs beach response to storms, Geophys. Res. Lett., 33.

Roelvink, J. A., 1993. Dissipation in random wave groups incident on a beach, Coastal Engineering, $19,127-150$.

Smit, M.W.J., Reniers, A.J.H.M. and M.J.F. Stive, 2010. What determines nearshore sandbar response? (this issue)

Short, A.D. and Trenaman, N.L., 1992. Wave climate of the Sydney region, an energetic and highly variable ocean wave regime. Aust. J. Mar. Freshwater Res. 43, 765-791.

Turner, I.L, D. Whyte, B.G. Ruessink and R. Ranasinghe, 2007. Observations of rip spacing, persistence and mobility at a long, straight coastline, Marine Geology, 236, 209-221.

Van Dongeren, A., A. Reniers, J. Battjes, and I. Svendsen, 2003. Numerical modeling of infragravity wave response during DELILAH, J. Geophys. Res., 108. 
van Enckevort, I.M.J., Ruessink, B.G., 2001. Effect of hydrodynamics and bathymetry of video estimates of nearshore sand bar position. Journal of Geophysical Research, 106.

van Enckevort, I.M.J., Coco,G., Ruessink, B.G., Suzuki,K., Turner, I.L., Plant, N.G., Holman, R.A., 2004. Field observations of nearshore crescentic sandbars. J. Geophys. Res. 109.

van Vledder, G.P., 1992. Statistics of wave group parameters, Proceedings of $23^{\text {th }}$ International Conference on Coastal Engineering, ASCE, 946-959.

Walstra, D.J.R, J.A. Roelvink and J. Groeneweg, 2000. Calculation of wave-driven currents in a 3D mean flow model. Proceedings of $27^{\text {th }}$ International Conference on Coastal Engineering, ASCE, 1050-1063.

Wright L.D. and A.D. Short, 1984. Morphodynamic variability of surfzone and beaches: a synthesis, Marine Geology, 56, 93-118. 